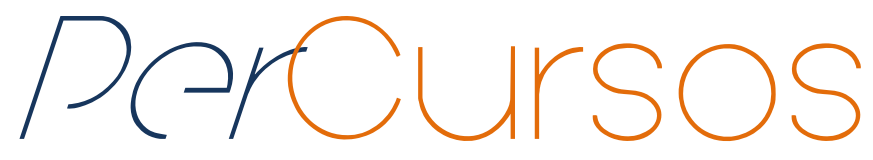

\title{
Homofobia e Família: entrevista com Sarah Schulman
}

Realizada por Gláucia de Oliveira Assis em Florianópolis, em 17/09/2013. Tradução de Fernando Coelho.

Sarah Schulman é uma escritora norte-americana, professora de inglês e historiadora. Foi uma das primeiras cronistas a escrever sobre a epidemia da AIDS nos Estados Unidos. Aborda os temas da AIDS, homossexualidades, lesbianidades e direitos de minorias. Seu livro mais recente, Ties that Bind: Familial Homophobia and Its Consequences (2009), trata da homofobia familiar.

\section{Para citar este artigo:}

SCHULMAN, Sarah. Homofobia e Família: entrevista com Sarah Schulman [Entrevista realizada em 17 de setembro, 2013]. Revista PerCursos, Florianópolis, v. 14, n.27, jul./dez. 2013. p. 360 - 371. Entrevistadores: Fernando Coelho, Gláucia de Oliveira Assis.

DOI: $10.5965 / 1984724614272013360$

http: //dx.doi.org/10.5965/1984724614272013360 
Gláucia de Oliveira Assis: Estou aqui com Sarah Schulman. Agradeço-lhe muito por ter aceitado o nosso convite. Esta entrevista é para as revistas acadêmicas da UDESC e da UFSC. Conte-nos um pouco sobre sua trajetória de vida e como se tronou ativista do movimento de lésbicas e pelos direitos dos homossexuais.

Sarah Schulman: Nasci numa família de emigrantes judeus, em 1958, treze anos após o holocausto, e a minha família foi grandemente [afetada]: minha avó teve duas irmãs e dois irmãos mortos no holocausto, então desde o dia em que nasci ouço histórias de pessoas que foram oprimidas, que sofreram por questões históricas, e desse modo eu fui preparada para uma confrontação com a questão da justiça e do direito das pessoas. Bem, quero dizer que os pais dizem aos filhos que é preciso ter certos valores, mas frequentemente os pais não têm os mesmos valores, e foi assim no meu caso, mas eu acreditei neles, eu aceitei esta responsabilidade, esta obrigação de me tornar alguém que participa da busca da justiça, e continua assim até agora.

G. Assis: Você atua na defesa dos direitos das pessoas portadoras do HIV. Em que medida a epidemia de AIDS, se num primeiro momento gerou preconceito com relação aos homossexuais (apesar da onda conservadora que gerou), possibilitou também ao longo dos anos a organização e a luta por direitos, contra a discriminação, pelo acesso ao tratamento e maior visibilidade das reinvindicações gays e lésbicas.

S. Schulman: Quando a AIDS começou em 1981, em Nova York, os homossexuais não tinham nenhum direito, não tinham direito a alojamento, a trabalho, nada. Podia-se recusar-Ihes o direito de serem servidos nos restaurantes, nos hotéis, havia uma discriminação total.

\section{G. Assis: Como no Brasil.}

S. Schulman: Como no mundo todo nesta época. Todos os homossexuais do mundo viviam na ilegalidade, e portanto, neste momento, era um grupo de pessoas exaustas, abandonadas por sua família e pelo governo, que sofreram com uma doença mortal, a qual obrigou que elas se reunissem, forçando que a sociedade mudasse contra a sua vontade, pois a sociedade não queria mudar, mas foi forçada a fazê-lo. Bem, isto levou a uma visibilidade da homossexualidade que não existia antes, pois, quando vemos o número de pessoas que morreram de AIDS em Nova York - foram 80 mil pessoas (e em 
todo o país 500 mil) -, então não se podia esconder um número como esse, e portanto ficou muito evidente que a homossexualidade existia e que estava integrada à sociedade. Foi assim que algumas atitudes começaram a mudar, mas é preciso compreender que isto complicava os resultados. No início, em 1981, não havia tratamento, não havia direito, nada. Durante os anos de luta, ou seja, entre 1987 e 1996, os militantes forçaram o governo e as companhias farmacêuticas a criar tratamentos. Agora, temos o tratamento. Mas, uma vez que temos um forte sistema de classes nos Estados Unidos, e o direito ao tratamento, à assistência médica, aos médicos não é um direito humano nos Estados Unidos. Desse modo, nós temos o tratamento, mas apenas para as pessoas que podem obtê-lo. Portanto, contornamos o vírus, mas não o sistema capitalista nos EUA, e o problema continua. Não se pensou nisso no começo.

G. Assis: Ainda no contexto da epidemia de AIDS, como tem refletido em seus estudos o modo como as desigualdades de gênero afetam as mulheres no sentido de negociar a prevenção?

S. Schulman: A experiência da AIDS entre as mulheres é uma experiência muito complicada desde o início, pois no início da crise os medicamentos não foram testados nas mulheres, e assim, quando eles liberaram alguns medicamentos para o público, eles nunca tinham tratado mulheres, você entende o que eu quero dizer?

G. Assis: Creio que no Brasil as mulheres têm grande dificuldade em negociar a prevenção com os seus parceiros.

S. Schulman: Eu acredito que os homens também têm problemas em conversar com outros homens sobre a questão da prevenção, é este o problema, é a comunicação. Quem quer que pratique sexo com um homem tem problema em negociar o uso de preservativos. Homens não gostam de usar preservativos. É por isso que as mulheres ficam grávidas, mesmo quando elas não querem. E é pela mesma razão que as pessoas contraem o HIV. A tecnologia do preservativo não é a tecnologia que vai ser bem sucedida na solução deste problema. É problemática demais para muitas pessoas. Em lugar de dizer às pessoas "use camisinha, use camisinha, use camisinha”, - pois sabemos que sempre haverá pessoas cujos parceiros não usarão preservativo (sempre haverá 
parceiros que não poderão forçar o outro a usá-lo) -, devemos procurar novas tecnologias. E a que mais ajudará as pessoas é a vacina. Assim, por 20 anos estamos em busca de uma vacina, mas não tivemos sucesso, e o processo da busca por vacina é um processo politicamente muito complexo, porque, quem quer sujeitar-se à vacina? Pois a questão do consentimento é muito diferente, e assim temos a exploração de certas populações para o estudo dessas vacinas, e é muito problemático. A vacina é a única coisa que acabará com a transmissão.

G. Assis: Fale um pouco de sua atuação como escritora e produtora teatral e como você articula as questões sobre lesbianidades em suas produções.

S. Schulman: Como escritora, publiquei 16 livros, entre os quais 9 romances. O primeiro livro foi em 1984. E o que é interessante é que, você sabe, no início dos anos 80 os EUA estavam à frente, eram a vanguarda em termos de gays, lésbicas e feminismo. Mas agora ficamos para trás. Ora, quando Ronald Reagan foi eleito em 1980, ele fez o país retroceder. Enquanto o resto do mundo levou à frente os movimentos inovadores da década de 70, nós andamos para trás. Então, no que diz respeito à ficção lésbica, estamos realmente atrás nos EUA. Não há novos romances que são mainstream ou populares com conteúdo verdadeiramente lésbico. Há ainda muita censura social, e você sabe por que isso é interessante, é que não se trata de censura legal, tem a ver com o fato de que há muitos fundamentalistas cristãos nos EUA, e eu sei que vocês tem o mesmo problema aqui [no Brasil]. É a metade do país. Se você olhar para a última eleição, Obama venceu por pouco. A pessoa que concorreu com ele tinha o apoio destes fundamentalistas cristãos. Assim, tem sido muito difícil avançar, muito mesmo. E este tipo de conteúdo artístico de vanguarda nunca se tornou um conteúdo comercial. O único grupo que avançou foi o dos homossexuais brancos das classes altas, porque, à medida que a homofobia diminui, se você é da classe dominante, você tem cada vez mais acesso ao poder daquela classe. Mas se você tiver outros problemas, por exemplo, se você for mulher, de cor ou da classe operária, e a homofobia diminui, isso não muda os outros aspectos da sua vida. E assim, eu continuo escrevendo este material, mas não há ninguém nos EUA que seja realmente um(a) romancista mainstream com protagonistas lésbicas. Já 
o teatro é ainda mais elitista, pois se limita às grandes cidades, como Nova lorque. E o público do teatro não é um público de massa, mas da elite. O público de um livro é um público de massa, podendo-se vender centenas de milhares ou milhões de livros. O público do teatro é muito pequeno. Você precisa ter apenas alguns poucos milhares de pessoas que venham assistir à sua peça. Assim, como resultado, há um público da elite que se desenvolveu, e os teatros não tentam expandi-lo, pois eles têm espaço limitado, e têm assentos limitados para vender. O teatro é muito conservador neste respeito. Desse modo, o que você vê são as mesmas histórias da classe média, muito similares, frequentemente sobre homens jovens que têm um conflito, quase sempre numa sala de estar, este tipo de coisa. Infelizmente esse é o tipo de teatro que temos.

\section{G. Assis: Quais os desafios contemporâneos colocados para os movimentos LGBTI?}

S. Schulman: O que vemos é que há 20 anos todos os homossexuais do mundo estavam na ilegalidade, sem direitos. Agora, isso muda, mas não para todos, senão para uma pequena parcela. Assim, em relação às pessoas que são brancas, que são homens, que estão na classe média alta, em alguns países, elas se tornaram mais brancas, mais homens, mais classe burguesa, pois a homofobia diminuiu, e assim a barreira entre certos indivíduos e o seu poder também diminuiu. Portanto, vemos que o movimento gay, a comunidade gay global se posiciona cada vez mais à direita. É o resultado. No início, era o movimento da liberação gay, era um movimento de liberação, não de direito, era uma ideia de mudar todas as limitações em todas as pessoas do mundo, era uma questão de sexualidade e de gênero, de relações pessoais, da família, das grandes questões de existência. Porém, após a AIDS, isso mudou, tornando-se um movimento de assimilação baseado no direito legal, ficando a questão da liberação de lado. Temos agora um movimento que é para o cidadão, contra o imigrado, contra o refugiado. É para os homossexuais que estão dentro de uma família, contra os que não estão no interior de um sistema familiar. É para as pessoas soro negativo contra as que são soro positivo. Assim, foi recriado um novo queer, e há agora os bons homossexuais, que estão ligados ao Estado, que têm os direitos do Estado, que têm acesso à máquina governamental que pode punir, que pode forçar a lei a seu favor contra as pessoas mais fracas, ou seja, os 
imigrados, os refugiados, as pessoas sem pátria, as que têm AIDS ou que estão sem família. Portanto, dividiu-se completamente a comunidade gay em duas classes, e os que estão ligados ao Estado não estão em um movimento progressista. Ele torna-se um movimento de direita, um movimento nacionalista. Desse modo, podemos ver que em um movimento verdadeiramente de direita, em todo lugar do mundo, não os movimentos religiosos, mas os movimentos laicos de direita, eles aceitam agora os homossexuais. Por exemplo, nos Países Baixos, na Holanda, há muito mais pessoas homossexuais que estão abertamente nos movimentos racistas, antimuçulmanos, contra os refugiados, e de modo semelhante na Inglaterra, e isso começa nos EUA também. Assim, ser homossexual ou pró-homossexual não significa necessariamente ser progressista. É preciso que os direitos dos homossexuaiss estejam ligados a outros conceitos humanos e ao conceito de justiça.

G. Assis: Interessante, porque há uma transversalidade entre os direitos dos homossexuais e os outros direitos humanos, os outros direitos sociais.

S. Schulman: Sim, uma vez que venho de uma família judia, eu vejo que há uma correspondência, porque houve um momento em que os judeus eram as pessoas mais oprimidas do mundo, e da mesma forma os homossexuais, as pessoas com AIDS eram as mais oprimidas do mundo, e já não é assim agora. Houve uma transformação muito rápida, e há alguns entre nós que têm o poder, e têm a capacidade de oprimir os outros. Mas, ao mesmo tempo, há homossexuais no mundo todo que são muito oprimidos, primeiramente pela família, depois pelo governo e finalmente pela mídia. Pode-se viver em Nova lorque numa família homofóbica e ser muito oprimido emocionalmente, psicologicamente. Portanto, há uma profunda opressão, mas não para todos.

G. Assis: No livro que você irá lançar no Fazendo Gênero 10, você relata sua experiência de encontro com os palestinos e sua lutas numa ocasião em que iria a Israel falar sobre movimentos homossexuais. Você juntamente com outros intelectuais fizeram um boicote ao evento condenando as ações de Israel na Palestina e realizaram um evento alternativo. Fale-nos como esse evento foi significativo para sua vida e militância, no sentido de demonstrar que as questões de gênero atravessam as questões de reconhecimento dos 
direitos humanos, do direito de poder viver com dignidade, como no caso dos palestinos que reivindicam seu Estado.

S. Schulman: Por causa das circunstâncias da minha família e das lições que eu aprendi quando era muito jovem, não compreendia exatamente que os judeus em Israel se tinham tornado uma classe que oprime outro povo. E precisou muito tempo para que eu compreendesse efetivamente isso. Mas muito tempo passou, e eu demorei muito para enfrentar esta questão. E por isso eu tenho vergonha, mas é a verdade, aconteceu assim. Mas desde que eu decidi realmente enfrentar esta questão, aprendi que era necessário que eu mudasse a mim mesma, que eu mudasse o meu conceito de mim mesma, e não foi tão difícil assim. É possível mudar como imaginamos a nós mesmos no contexto mundial. É possível mudar isso. É possível deixar de lado uma imagem de vítima e aceitar que participamos de um grupo que se tornou um grupo opressor. É duro, mas é possível ver e compreender. Enfim, estou feliz por ter tido essa experiência, pois eu vejo que é uma transformação que pode acontecer, e que todos os outros que estão na mesma situação podem também enfrentar. Há nisso um pouco de vergonha, mas há também um objetivo maior que a vergonha, que ao final suprime a vergonha, e que se torna mais importante. Então, desde o momento em que eu aceitei isso, vi que eu tinha certa responsabilidade. Em primeiro lugar, sou americana e tive uma bolsa americana, e é o dinheiro do governo americano que apoia a ocupação na Palestina. Portanto, é direto entre mim, que sou cidadã americana e a opressão na Palestina. E em segundo lugar, como judia, e sobretudo de uma família que passou pelo holocausto, tenho absolutamente a obrigação de que não se manipule a mim, minha existência, a experiência da minha família, para justificar um racismo, um sistema de apartheid. É absolutamente importante que eu não permita que a história do holocausto seja utilizada para provocar um nacionalismo, para justificar o racismo. Tenho, portanto, uma dupla obrigação, e faço o que eu quero, vou o tempo todo para a Palestina, escrevi um livro, faço palestras por todo o mundo, especialmente nas universidades, organizo conferências, e faço tudo o que eu posso, participo de boicotes das instituições acadêmicas de Israel. E acho que esta é uma posição muito interessante, sendo de uma judia, pois tenho a possibilidade de me comunicar com outros judeus numa discussão interior, privada de fato, sobre essas questões, ou seja, por que é 
absolutamente essencial que mudemos nossa posição. E quando são pessoas de fora que têm a mesma posição que eu, os outros judeus podem se tornar muito paranoicos, podem temer que isssto se torne um antissemitismo, mas quando é entre judeus, quando há judeus dentro da comunidade que são contra a ocupação, há muito mais poder na discussão. E é também importante que os palestinos saibam que há judeus que são contra e que acreditam num mundo em que todas as pessoas tenham direitos iguais. É, portanto, enriquecedor, enfim.

G. Assis: Você fará uma conferência sobre relações familiares, ou seja, entre os pais e os filhos que são homossexuais. Você poderia falar um pouco sobre isso, como você vê essas relações nos EUA, esta homofobia familiar?

S. Schulman: Não é apenas entre os pais e os filhos, é em todo o sistema familiar. Não é apenas nos EUA, é universal. Podemos dizer que cada cultura é diferente, mas a homofobia familiar é realmente universal, há em todas as sociedades. A família é o primeiro lugar em que todo mundo aprende a homofobia, é o primeiro lugar em que os homossexuais sofrem com a homofobia, é o primeiro lugar em que os heterossexuais aprendem que eles terão o poder, pois desde que nascemos há a expectativa da heterossexualidade, mesmo que os pais sejam feministas, mesmo que os pais sejam homossexuais. Há uma força, porque há um problema na estrutura familiar que nunca poderá ser resolvido, ou seja, a família é a arma do Estado. O Estado usa a família para normatizar a sociedade. De modo que, mesmo que você tenha uma família queer, eles são os normais, em oposição aos que não têm família. Estar numa estrutura familiar já é muito problemático em termos de construção de poder, e sobretudo o papel da mãe, mesmo a mãe queer, mesmo a mãe feminista, a mãe é um papel de mártir. É a expectativa de todos que a mãe irá sacrificar algo da sua vida pelos filhos, e isso continua mesmo quando os filhos são adultos. Portanto, é um papel que não funciona. Temos assim um sistema, o sistema familiar, que é cheio de disfunção, e portanto é um sistema que nunca poderá produzir uma sociedade igualitária. Não é possível, sobretudo porque as pessoas que estão numa família têm mais privilégios do que as que não estão. Não é um sistema progressista. Eu não sou contra a família, mas é preciso compreender o que é a família. Temos um sistema que replica a homofobia, que ensina a homofobia, que ensina seus 
filhos como experienciar a homofobia, que ensina como usar a homofobia. Então, ainda que todas as leis mudem, ainda haverá homofobia na família, e haverá consequências emocionais na vida dos homossexuais, e também haverá um falso sentimento de superioridade na vida dos heterossexuais. A questão é, portanto, como mudar isso, e acredito que a mudança deve vir de fora da família. Por exemplo, agora sabemos que, quando há violência na família, vêm outras pessoas e dizem: "não você não pode fazer isso." O Estado entra, os vizinhos entram, os amigos entram e dizem: "não, isto está errado." Pois agora sabemos que há uma força moral maior que a família. O mesmo deveria acontecer em relação à homofobia. Quando se visse homofobia em uma família, todo mundo deveria dizer: "não, isto está errado." Os amigos homossexuais da pessoa homossexual deveriam dizer à família: "vocês estão errados." Os professores deveriam dizer à família: "vocês estão errados." Temos que entender que há uma força moral maior do que a família. Você sabe, esta é a resposta. Trata-se de um estigma. Você muda o estigma.

G. Assis: Acerca da violência familiar, há instituições governamentais, o Estado tenta reeducar a família.

S. Schulman: Agora, se você é homossexual em uma família, você está sozinho, e você não deveria estar sozinho.

G. Assis: Eu tive uma aluna no semestre passado, ela tinha uma namorada, e quando a família descobriu, trancou a filha, literalmente, em casa. Uma coisa inacreditável. Tiraram seu celular, sua Internet, ela ficou incomunicável.

S. Schulman: Isso é estremo. Mas há homofobia em famílias que não são extremistas. Na maior parte do tempo, apenas se olha para os casos estremos, mas, por exemplo, se você é lésbica e tem uma parceira, e o seu filho adulto que vir para a sua casa para morar, e ele não gosta da sua parceira, quem você acha que vai ganhar? O filho. E isso acontece todos os dias. Enfim, creio que a homofobia está presente nas interações familiares cotidianas, mesmo em famílias mais progressistas.

Fernando Coelho: Então você acha que o Estado deveria agir.

S. Schulman: Ele poderia. 
F. Coelho: Por exemplo, tivemos uma iniciativa do governo, a criação do chamado kit gay, uma brochura com informações sobre a homossexualidade, que deveria ser distribuída em todas as escolas, mas até o momento é uma coisa que não aconteceu.

S. Schulman: Mas o Estado não é a solução. A solução são as outras pessoas. Agora temos a ideia de que a família é sagrada, não se podendo dizer nada à família. Mas eu acho que é preciso falar o tempo todo à família, é preciso estar em discussão o tempo todo com a família. A família não deveria ser o sistema mais forte da sociedade, pois há pessoas aí dentro, as mulheres, os homossexuais, na família, que perdem.

G. Assis: Amanhã você vai participar de uma conversa sobre sexualidade e educação...

S. Schulman: E também sobre homofobia familiar. Pois, quando os professores veem que seus alunos têm problemas com a homofobia, eles deveriam falar com os pais. Quando os pais vão à escola, o professor deve dizer: "nós apoiamos o seu filho homossexual, e vocês estão fazendo mal para o seu filho." E do mesmo modo se os pais estiverem batendo no filho, os professores têm a responsabilidade de fazer e intervir.

G. Assis: Os professores não necessariamente compreendem a homossexualidade como um direito. É muito interessante esta conversa com eles, porque, em geral, alguns professores são muito conservadores, e muitas vezes entendem a homossexualidade como uma doença, como um problema mental, ou como um pecado.

S. Schulman: Creio que seja um problema de estigma, pois agora a homossexualidade é um estigma. E o que aconteceria se a homofobia fosse o estigma? Se todos disséssemos: “A homofobia é antissocial, a homofobia faz mal às famílias, a homofobia gera violência, não seja homofóbico, não seja homofóbico", então teríamos uma ênfase socialmente diferente, e os professores seriam afetados por isso. Quero dizer, nem todo mundo mudaria, mas muitas pessoas são homofóbicas porque elas pensam que devem ser, pensam que isso os torna bons cidadãos. E se isso fosse um estigma, muitas pessoas não agiriam dessa forma. Nem todo mudo, mas muitas pessoas.

F. Coelho: Vemos isso claramente aqui no Brasil. O governo tem feito muita propaganda para dizer exatamente isso, ou seja, que ser homossexual não é um problema, que é algo normal, que não é uma doença...

G. Assis: Há um debate público e mudanças importantes neste campo. 
F. Coelho: Vemos isso na televisão, nas novelas. Em todas as novelas agora há um casal homossexual...

S. Schulman: E se não fosse um casal?

F. Coelho: Nem sempre um casal, é algo mostrado como normal, porque antes não tínhamos isso, não víamos na televisão personagens que fossem homossexuais. Há dez, vinte anos.

G. Assis: Quando tínhamos, era muito cômico, ridículo. Hoje as novelas tentam apresentar homossexuais, casais ou não, como outras pessoas...

S. Schulman: O que eu vejo agora são apenas casais, apenas filhos, apenas famílias homossexuais, apenas casados.

G. Assis: Agora é a primeira vez que temos uma novela com um casal homossexual...

F. Coelho: Eles são uma família, dividem uma casa, querem ter filho. Mas tivemos muitos personagens que eram homossexuais, por exemplo, mais jovens, que não tinham relacionamento com ninguém, e isso novo, é recente.

G. Assis: É polêmico, pois muitas pessoas dos movimentos gays não gostaram, e os religiosos não gostaram. Enfim, casais, não casais, de qualquer jeito.

S. Schulman: Há a crítica da esquerda e a crítica da direita.

G. Assis: Há algo que você gostaria de falar sobre os seus romances, sobre as suas produções, que você gostaria que os brasileiros conhecessem?

S. Schulman: Tenho um livro que foi traduzido para o português, mas é só isso. Eu gostaria de ter meus livros traduzidos no Brasil. Lamento que eles não estejam disponíveis. Não sei como é a situação editorial aqui, mas é algo que seria certamente muito bom. Ademais, produzi um filme que eu vou mostrar aqui sobre a história do ato chamado United in Anger. Você conhece? Acho que isto seria interessante de mostrar aqui no Brasil, acho que é a segunda vez que vai ser apresentado aqui. Já foi mostrado em Beirute, Bombaim, em todas as partes do mundo. Ele mostra como pessoas sem nenhum poder podem mudar o mundo. É um filme muito interessante. 
G. Assis: Muito obrigada, foi um grande prazer conhecê-la. Estamos muito felizes por ter você aqui no Fazendo Gênero. É importante para nós, muito importante mesmo, em todos os sentidos, afetivos e políticos, e seja bem-vinda aqui.

S. Schulman: Muito obrigada.

Recebido em: $17 / 11 / 2013$ Aprovado em: 20/12/2013

Universidade do Estado de Santa Catarina - UDESC Centro de Ciências Humanas e da Educação - FAED

Revista PerCursos Volume 14 - Número 27 - Ano 2013 revistapercursos@gmail.com 